\title{
A41 \\ BREVE HISTÓRIA DE UM ARMÁRIO DE DOAÇÕES E SUAS IMPLICAÇÕES
}

\author{
A41 \\ A brief history of a cabinet. Visual objects \\ donations and its implications in a museum.
}

Solange Ferraz de Lima*

\begin{abstract}
RESUMO
A proposta do presente artigo é refletir sobre as práticas recorrentes e cotidianas que consubstanciam a cultura visual contemporânea a partir de objetos visuais doados ou adquiridos por um museu de história e sobre as práticas museológicas que proporcionam novo patamar de observação e fruição desses mesmos objetos, agora tomados como documentos. Duas questões emergem de imediato quando colocamos atenção nas práticas acumuladoras e colecionistas dentro ou fora de espaços institucionalizados: em que medida esses objetos visuais podem ser considerados de interesse para tratar da visualidade da sociedade contemporânea e quais os efeitos sociais provocados pelas políticas de coleta de acervos dos museus.
\end{abstract}

Palavras-chave: cultura visual; museus; curadoria.

\begin{abstract}
The purpose of this article is to reflect on a collection of visual objects in a Museum of History in order to discuss the daily social practices embodied in the visual culture and the museum practices involved in the curator process of qualify these objects as documents of the visual dimension of the contemporary society.
\end{abstract}

Keywords: visual culture; museums; curatorship.

\footnotetext{
" Livre-docente e curadora no Museu Paulista da Universidade de São Paulo.
} 


\section{Introdução $o^{1}$}

Em fins da década de 1990, mediei uma aquisição para o Museu Paulista (o antiquário Ornabi era o vendedor) de dois álbuns-diários que versam sobre a viagem à Europa de um casal de meia-idade. Os álbuns medem, cada um, aproximadamente $20 \times 15 \mathrm{~cm}$, um de capa vermelha e outro de capa azul, e datam de 1951. O volume azul é o primeiro, presente do filho, segundo a própria escritora do álbum-diário. $O$ volume azul é iniciado com as assinaturas dos amigos que estiveram na despedida do casal que embarcava para a longa viagem de quatro meses a bordo do navio Toscanelli. Ambos os álbuns-diários relatam com pormenores as impressões de Maria (nome fictício) acerca das cidades, habitantes, serviços e amizades feitas ao longo da viagem. $\mathrm{O}$ texto, escrito à caneta, é ilustrado com postais, recortes de revistas, guias turísticos, propagandas. A leitura do relato permite algumas inferências: parecia ser a primeira grande viagem do casal, bem-educado, mas não da elite e sim oriundo das camadas médias da cidade de São Paulo.

Ao tratar dos protocolos da aquisição (documento de compra, laudos de conservação e interesse histórico, depoimento, quando possível), não pude deixar de comparar este álbum com outro conjunto de álbuns, integrado ao acervo trinta anos antes. Os álbuns da Coleção Olga de Souza Queiroz foram doados, entre outros muitos itens, após seu falecimento em 1968, resultado de suas muitas viagens à Europa, realizadas entre 1913 e $1950^{2}$. Ambos os conjuntos diferem em escalas - os dois álbuns montados da Coleção Olga são maiores e reúnem muito mais imagens, medem $40 \mathrm{x}$ $50 \mathrm{~cm}$ cada um, com cerca de 500 impressos no formato postais e outros - e também quanto à proveniência em termos de extrato social. A família Olga de Souza Queiroz era oriunda da elite cafeeira paulista e gozava do prestígio pelo poder econômico e social.

1 Agradeço a Vânia Carneiro de Carvalho e a Eduardo Gehrke pela interlocução no curso de elaboração desse artigo e pelas preciosas sugestões bibliográficas. Agradeço também Rodrigo Irponi e Tatiana Vasconcelos, do Serviço de Documentação do Museu Paulista, pela colaboração na busca por antigas tabelas e separação de documentos.

2 A coleção Olga de Souza Queiroz é ampla e variada (envolve mobiliário, indumentária, documentação textual, objetos de decoração). Foi doada ao Museu Paulista em 1968. Os documentos visuais integram uma série que reúne um total de 27 álbuns -4 montados, sendo dois de fotografias amadoras e dois de cartões postais e 23 impressos. Os temas dos álbuns impressos dividem-se entre cidades, obras de arte integrantes de museus, pontos turísticos (ex. Palácio de Versailles). Tipologia temática semelhante é encontrada nos álbuns montados. A série abrange de 1913 até fins da década de 1950. 
Minha intenção, ao buscar esses álbuns adquiridos em 1999, era refletir sobre a permanência de uma prática - a montagem de álbuns de viagens com cartões postais - no tempo e em diferentes camadas sociais no âmbito da pesquisa e curadoria dos álbuns da coleção Olga de Souza Queiroz que venho desenvolvendo desde $2012^{3}$.

Chegar aos referidos álbuns quase 15 anos mais tarde, tendo participado apenas dos protocolos de entrada, era a minha missão. Comecei pelo arquivo referente aos processos de aquisições (por compra ou doação). Ao solicitar acesso ao arquivo à supervisora do Serviço, ela fez menção ao A41. Lembrei-me de imediato do A41. No final dos anos 1990, e após 2002, houve um visível incremento de doações de fotografias e impressos de origem fotográfica. Esse incremento estava claramente relacionado à ampla divulgação de duas exposições de retratos fruto da pesquisa e curadoria da Coleção Militão Augusto de Azevedo ${ }^{4}$. As então recentes doações tiveram como destino o Armário 41, ou A41, como é designado no mapa topográfico do Serviço. Ele funcionou como uma espécie de quarentena à espera da patrimoniação, higienização, embalagem definitiva e catalogação.

O A41 já não existe mais, pois a quarentena fora transferida para uma área maior, uma reserva técnica que chamamos "reserva suja" e que acolhe as aquisições por compras e doações recentes que não estejam contaminadas por agentes biológicos (cupins, traças, etc.). Mas sua identidade como repositório, principalmente de doações havidas em um período determinado - fins de 1999 a 2005 -, se manteve, graças a tabelas de controle do acervo. Uma em especial, chamada A41. Ao consultá-la, me dei conta de que esse recorte involuntário do acervo existente era representativo de várias

3 A série de álbuns da coleção já foi inteiramente catalogada no que diz respeito aos dados técnicos, incluindo-se aí a identificação das diversas técnicas de impressão; já se encontra inteiramente reproduzida fotograficamente. No momento, estamos dando início à pesquisa sobre as casas editoras e impressoras do material reunido. Equipe: Solange Ferraz de Lima, coordenadora; Marcos Silva Blau, conservador de fotografias, responsável pela catalogação sumária e identificação de técnicas; Sonia Maria Spigolon, conservadora de fotografias, responsável pela identificação de técnicas e tratamento de preservação; Ina Hergert, conservadora de papéis, responsável pelo projeto de restauração e conservação das encadernações.

4 Sobre a curadoria da Coleção Militão Augusto de Azevedo e seus produtos cf. LIMA, Solange Ferraz de; CARVALHO, Vânia Carneiro de. Fotografia no Museu: o projeto de curadoria da Coleção Militão Augusto de Azevedo. Anais do Museu Paulista Revista de História e Cultura Material. São Paulo: Museu Paulista, v. 5, p. 205-245, 1997; LIMA, Solange Ferraz de; CARVALHO, Vânia Carneiro de. Cultura visual e curadoria em museus de história. Estudos Ibero-Americanos, Rio Grande do Sul, v. 31, n. 2, p. 53-77, 2005. 
ações, paralelas ou encadeadas, mas todas integrantes do processo ativo de musealização de documentos iconográficos capazes de iluminar práticas cotidianas de uma sociedade calcada no regime escópico. As reflexões sobre esse conjunto de documentos que ocupou temporariamente um armário, reunido até certo ponto de modo aleatório, ocupam as próximas páginas.

A ideia de partir de um conjunto formado pela prática de coleta museológica foi livremente inspirada no artigo de Elizabeth Edwards, chamado "Mixed Box"5. Edwards se propõe analisar uma caixa contendo retratos reunidos pelos curadores do Pitt Rivers Museum, o mais antigo museu de Antropologia da Inglaterra, parte integrante da Universidade de Oxford. A partir das intencionalidades dos profissionais do museu, cuja caixa de retratos é resultado, Edwards desenvolve uma reflexão crítica sobre as práticas e os sentidos construídos sobre o outro em museus de antropologia e o papel fundamental da fotografia nesse processo.

No presente caso, o conjunto escolhido para análise não decorre de um arranjo proposto segundo qualquer intencionalidade de cunho pedagógico ou expositivo por parte dos curadores e documentalistas do Museu Paulista, mas sim de um conjunto formado em um momento do processo curatorial que antecede a difusão mais ampla.

A proposta do presente artigo é refletir, simultaneamente, sobre as práticas recorrentes e cotidianas que consubstanciam a cultura visual contemporânea, e cujos objetos doados são testemunhos materiais, e sobre as práticas museológicas que proporcionam novo patamar de observação e fruição desses mesmos objetos, agora tomados como documentos. Duas questões emergem de imediato quando colocamos atenção nas práticas acumuladoras e colecionistas dentro ou fora de espaços institucionalizados:

- Quais os efeitos sociais provocados pelas políticas de coleta de acervos dos museus?

- Em que medida esses objetos visuais podem ser considerados de interesse para tratar da visualidade da sociedade contemporânea?

5 EDWARDS, Elizabeth; HART, Janice. Mixed Box: the cultural biography if a box of ethnografic photographs. In: Photographs objects histories. On the materiality of images. London \& New York: Routledge, 2003. 


\section{Abrindo o A41...}

Os meios de integração ao acervo dos 4.850 itens acondicionados no A41 por um período de aproximadamente cinco anos foram por doação e aquisição e sempre obedeceram às linhas de pesquisa institucionais, base da política de acervo definida no Plano Diretor do Museu Paulista ${ }^{6}$. Assim, é de se notar a correlação entre as tipologias de documentos iconográficos doados ou adquiridos por compra e as ações curatoriais que procuraram, desde 1990, dar um caráter sistemático e coerente às aquisições de modo a garantir séries representativas de estratos sociais ou recortes tipológicos de materiais visuais. As linhas de pesquisas do Museu Paulista - História do Imaginário, Cotidiano e Sociedade e Universo do Trabalho - foram definidas em 1990 a partir do potencial dos acervos já existentes na instituição. E os projetos de pesquisas desenvolvidos em cada uma delas mobilizam itens do acervo já integrados, mas ainda sem tratamento documental e de pesquisa, ou o incrementam com novos itens, sejam eles documentos avulsos, coleções ou fundos.

No caso das aquisições por compra, elas podem ser motivadas por necessidade de cobertura de uma tipologia já existente no acervo ou por pesquisas em andamento e, nesses casos, o curador é, via de regra, o coletor. No caso das doações, elas podem ser totalmente espontâneas, induzidas pelo contato havido entre curador e doador no curso de uma pesquisa, ou ainda induzidas por colegas ou outros profissionais que indicam o Museu Paulista como destino, ou até mesmo induzidas por aquilo que a mídia veiculou a propósito de exposições e atividades.

Procuramos sempre manter o conjunto identificado segundo o critério da proveniência. Dependendo da organicidade do conjunto, o consi-

6 O Plano Diretor do Museu Paulista foi elaborado em 1989, na gestão do Prof. Dr. Ulpiano Toledo Bezerra de Meneses, quando da última grande reformulação dos acervos pertencentes aos quatro museus estatutários da Universidade de São Paulo - Museu Paulista, Museu de Zoologia, Museu de Arqueologia e Etnologia e Museu de Arte Contemporânea. Ao longo da trajetória do Museu Paulista, o mais antigo dos quatro museus e que foi integrado à Universidade de São Paulo em 1963, os acervos de botânica e zoologia foram transferidos para instituições como o Instituto de Botânica e o Museu de Zoologia. Em 1989, ocorreu o último desmembramento de seu acervo, com a transferência das coleções etnográficas e de arqueologia pré-histórica para o Museu de Arqueologia e Etnologia. O Museu Paulista é definido, a partir de então e segundo seu plano diretor, como um museu de história especializado em cultura material da sociedade brasileira. As linhas de pesquisa, bem como as políticas de aquisição de acervos para sua biblioteca, derivam desse novo perfil de atuação. 
deramos uma coleção ou um fundo ${ }^{7}$. Essa atribuição já é uma ação curatorial iniciada no ato da doação ou compra do conjunto, momento em que se procura reunir o maior número de informações para a identificação dos itens doados (conteúdo, datação, etc.), bem como também sobre as motivações para a seleção do conjunto. O material acondicionado "em quarentena" no A41 já recebeu esse primeiro tratamento; assim, os 4.850 itens já são identificados como pertencentes a 33 coleções ou são documentos avulsos ${ }^{8}$.

$\mathrm{Na}$ tabela em Excel que representa o conteúdo do A41 estão descritos sumariamente os 4.850 documentos iconográficos: conjuntos fotográficos de origem privada (retratos de família em álbuns ou avulsos); rótulos de produtos, repertórios de modelos arquitetônicos e decorativos em ferro e estuque, álbuns de figurinhas, impressos religiosos (distribuídos em velórios, ritos como primeira comunhão, crisma ou missas especiais), material didático ilustrado e cartões postais (em álbuns e avulsos). Parte dos álbuns é criada segundo arranjos dados pelos doadores, os quais podemos chamar álbuns "montados", indicando uma ação depois de já adquiridos (consumidos), separadamente, os itens de composição material do álbum - a encadernação, os cartões postais ou fotografias avulsas e outros impressos. E parte dos álbuns é adquirida já montada (editada), como os álbuns ou catálogos de artes, de paisagens urbanas ou rurais, de estabelecimentos, de figurinhas, etc. O recorte cronológico do material disposto no A41 é amplo e percorre um arco de pelo menos 100 anos, de fins do século XIX até a década de 1980.

As fotografias de famílias avulsas e em álbuns, incluindo aí alguns álbuns de cartões postais montados no ambiente familiar, perfazem cerca de $60 \%$ do total. Outra tipologia que comparece com uma recorrência expressiva é a formada por cartões postais e álbuns editados de cartões

7 A coleção pode ser definida como um conjunto artificialmente arranjado, enquanto que o fundo refere-se a conjuntos documentais cuja acumulação acontece necessariamente, ou seja, em função de uma atividade em curso. Cf. CAMARGO, Ana Maria de Almeida; BELLOTTO, Heloísa Liberalli (Coords.). Dicionário de Terminologia Arquivística. São Paulo: Associação de Arquivistas Brasileiros/Núcleo Regional de São Paulo; DEMA/SEC, 1996.

8 Os documentos avulsos são aqueles adquiridos pelo curador em feiras de antiguidades, lojas, ou itens isolados doados espontaneamente e para os quais a classificação segundo proveniência não é funcional, na medida em que não referencia e nem elucida sobre as performances e contextos de uso e apropriações dos objetos. Uma opção, nesses casos, é classificar como coleção a partir do tipo documental, por exemplo, coleção de rótulos, ou por estar relacionado a algum tema ou fato histórico, como, por exemplo, coleção Revolução de 32. Mas evitamos esse tipo de classificação, pois ela pode induzir a uma visão restrita do conjunto. Preferimos representar esses itens como documentos avulsos. 
postais, reunidos por colecionadores. Em menor escala, comparecem as demais tipologias acima elencadas.

Essas tipologias podem ser qualificadas como o que Gaskell usou chamar material visual, ou seja, a gama de suportes iconográficos que não gozam do mesmo estatuto que as obras de arte definidas segundo os cânones renascentistas - "arte erudita" e as "artes aplicadas". A fotografia, de enorme impacto cultural, e da qual deriva uma gama considerável de tipos documentais ou que dela se valem como meio técnico de reprodução, pode ser considerada como parte desse material visual sem classificação possível no universo da arte postulada por historiadores, críticos, galeristas e museus de arte?

Mas a fotografia e suas formas derivativas podem, ao mesmo tempo, gozar do privilégio de integrarem acervos museológicos históricos ou antropológicos e alcançarem valor de mercado graças a curadores, colecionadores e negociantes de antiguidades. Nestes casos, o prazer em fruir objetos do passado funciona como elemento-chave no processo de valorização que impulsiona a circulação de certos produtos fotográficos. É o caso, por exemplo, dos cartões postais, que gozam de consolidado lugar no universo colecionista particular, mas ainda são presença escassa em coleções museológicas. Ou ainda os retratos oitocentistas, nos tradicionais formatos cartão de visitas e gabinete, possíveis de serem encontrados em feiras de antiguidades, sem guardar vínculo algum com os retratados ou o detentor original. Seu valor advém principalmente de sua antiguidade. O mesmo pode-se afirmar para os álbuns de figurinhas, impressos religiosos (missas de sétimo dia, dia do santo), embalagens e material didático ilustrado. Todas essas tipologias integram o universo colecionista, acionam e mobilizam redes de sociabilidades que podem ser amplas ou muito reduzidas, bem como o mercado de antiquariato, mas sempre tiveram pouca presença em museus e arquivos.

A oportunidade oferecida pelo A41 é de exercitar o olhar sobre tipologias que, reunidas involuntariamente, revelam aspectos concernentes à dimensão visual da sociedade de natureza material e indicativos da dinâmica do contexto de produção desses chamados materiais visuais. Vejamos.

É indubitável a importância do retrato e de sua longa tradição na

9 GASKELL, Ivan. História das imagens. In: BURGE, Peter (Org.). A escrita da História. Novas perspectivas. São Paulo: EDUNESP, 1992. p. 237-272. 
nossa sociedade ocidental. Do ponto de vista formal, o retrato fotográfico vincula-se muito diretamente aos ditames da retratística tradicional forjada na pintura acadêmica. As variações no tempo são perceptíveis, sobretudo nos retratos de família, em que assiste-se a uma flexibilização da pose ao longo do século XX, por exemplo. Mas, mesmo assim, a força dessa tradição iconográfica é perceptível. Pois bem, uma das mais importantes inflexões na história da fotografia no século XIX foi o formato carte de visite, e podemos dizer que outra inflexão, do mesmo porte, acontece no século XX, com o retrato $3 \times 4 \mathrm{~cm}$ destinado a atuar como testemunho documental de nossa existência nos documentos e cadastros de toda sorte que regulam nossa vida social.

A presença no A41 de documentos iconográficos produzidos em diferentes períodos e para diferentes circuitos das esferas pública e privada - ambientes doméstico, escolar, religioso - nos permite especular aqui as razões não só para a recorrência de determinados arranjos de enquadramento da figura humana ${ }^{10}$, mas também para a permanência de determinados formatos dos suportes materiais dos retratos. Ainda em relação aos suportes materiais, é também notável a institucionalização do álbum como meio de acondicionamento e arquivamento, não só dos retratos, embora eles tenham desempenhado papel importante na sua popularização e difusão maciça.

Graças ao recorte proporcionado pelo A41, é possível comparar e especular sobre permanências decorrentes da prática de colecionar retratos de celebridades, por exemplo. É o caso do álbum de retratos de celebridades no formato carte de visite de meados do século XIX (década de 1870) de origem francesa (Coleção Jeferson Pereira) e de um conjunto de 202 retratos (papel revelação) colorizados de celebridades do cinema americano (décadas de 1940-1950) no formato 3 x 4 (Figuras 1 e 2). Não há informações sobre a produção dos pequenos retratos, nos quais constam apenas a legenda de identificação do retratado e o estúdio cinematográfico que o contrata. É possível que acompanhassem, na forma de brindes, revistas ou maços de cigarros. Já no caso dos carte de visite, a identificação não integra o produto final e esta foi feita manualmente pelo detentor original do álbum. Os

10 A tradição da retratística na pintura expressa no retrato fotográfico do século XIX foi tratada em LIMA, Solange Ferraz de; CARVALHO, Vânia Carneiro de. Individuo, género y ornamento en los retratos fotográficos, 1870-1920. In: AGUAYO, Fernando; ROCA, Lourdes (Org.). Imágenes e investigación social. 1. ed. v. 1. México, 2005. p. 271-291. 


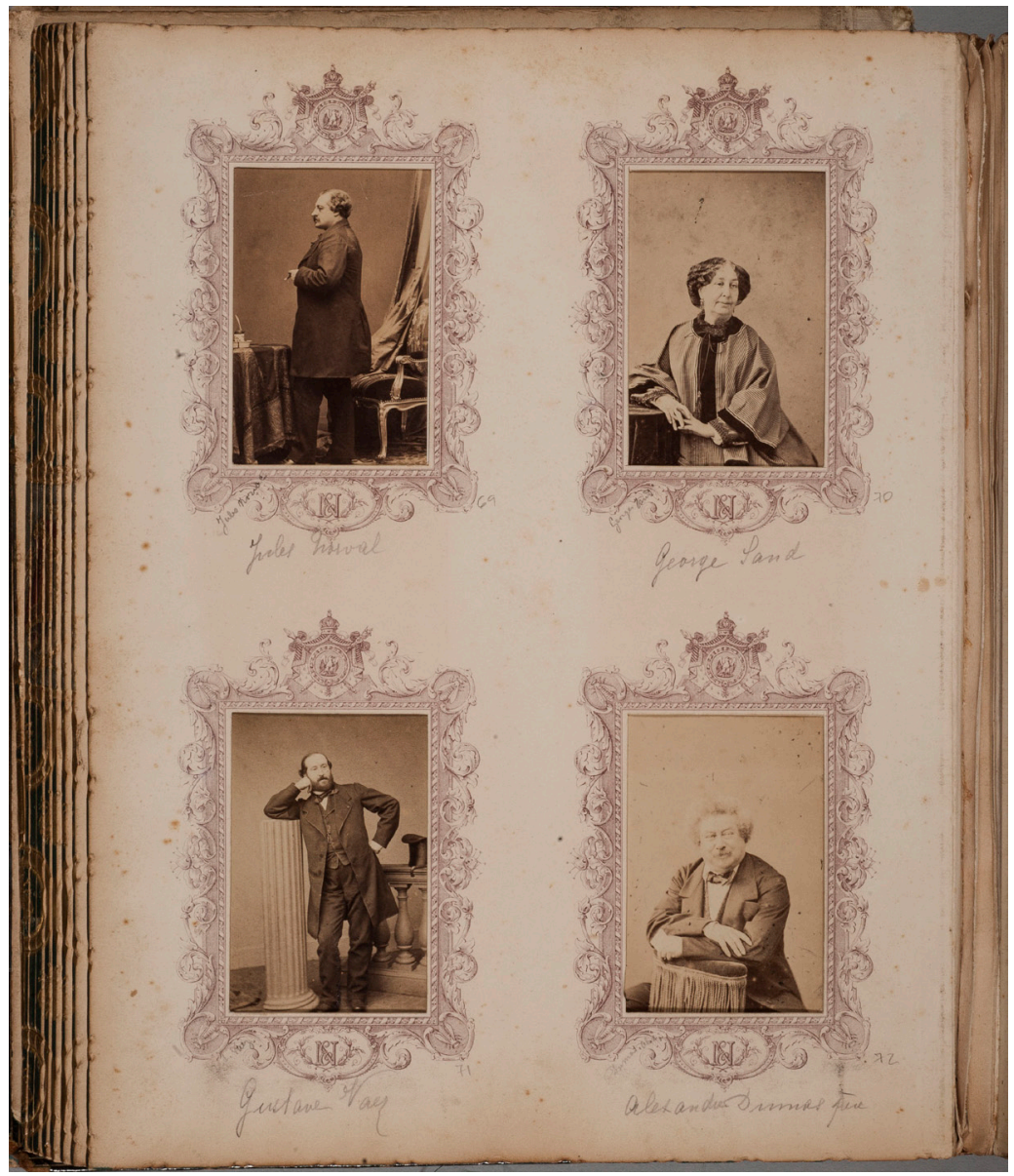

FIGURA 1 - PÁGINA DE ÁLBUM DE RETRATOS DE CELEBRIDADES. DÉCADA DE 1870. COLEÇÃO JEFFERSON PEREIRA. ACERVO MUSEU PAULISTA DA USP. REPRODUÇÃO JOSÉ ROSAEL. 


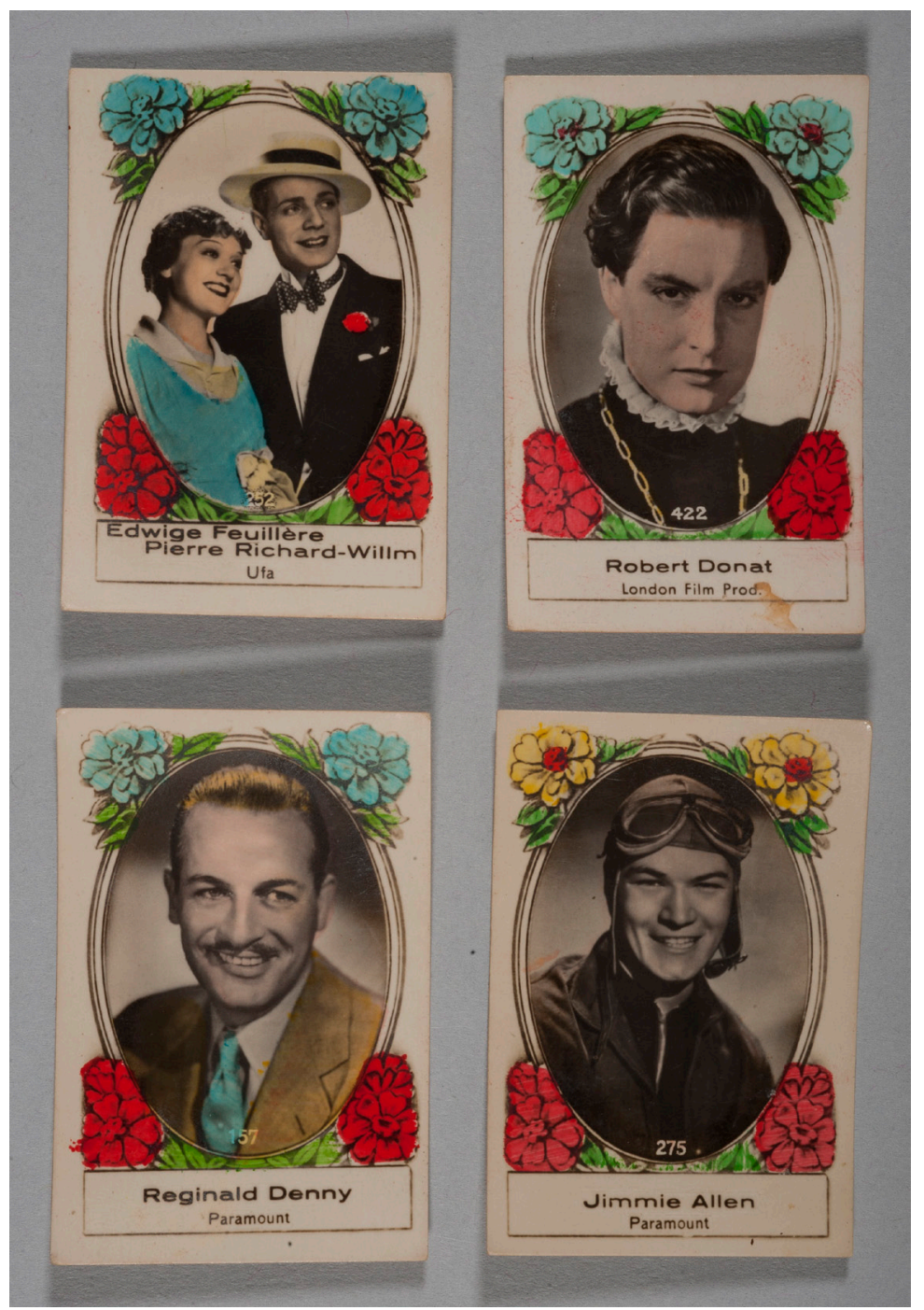

FIGURA 2 - RETRATOS DE ATORES DE CINEMA. PAPEL REVELAÇÃO, NAS DIMENSÕES 3 X 4 CM. SEM DATA. COLEÇÃO GERALDINA WITTER. ACERVO MUSEU PAULISTA DA USP. REPRODUÇÃO JOSÉ ROSAEL. 
versos dos retratos trazem a identificação do estúdio fotográfico, como de praxe. $\mathrm{O}$ que esses artefatos permitem constatar é a permanência de uma prática ao longo de um século, motivada pelo fascínio e curiosidade que a fisionomia de pessoas que alcançaram notoriedade pública desperta. Se o fascínio e a curiosidade pelas fisionomias explicam as demandas, podemos afirmar que a manutenção e a reprodução desta prática social dependem da circulação material dessas imagens.

O desejo que alimenta esta prática colecionista específica é de conhecer por meio da aparência, ou seja, a motivação é da ordem do visível, que cria as condições, por sua vez, para o estabelecimento de uma rede de profissionais envolvidos na produção do visual - suportes de variados tamanhos, circulados avulsos ou em álbuns, vinculados a outros produtos, etc., etc. Um encadeamento de ações em torno da notoriedade que se realiza na dimensão da visualidade.

No tocante ao perfil das celebridades percebemos mudanças e isso também nos informa sobre a dinâmica de atribuição de notoriedade ao longo do período que separa os dois conjuntos de retratos de celebridades. Comparando ambos nota-se, de imediato, uma ampliação do rol da fama - novas áreas de atuação concorrem para a promoção de celebridades. E essa expansão fomenta a criação de nichos específicos. O álbum de 1875 é "misto", ou seja, reúne celebridades oriundas de áreas distintas, mas que não extrapolam a vida política, religiosa, aristocrática e, com menor representatividade, a vida cultural, manifesta por meio de escritores e compositores. Em meados do século XX, álbuns "mistos" não mais existem. Colecionam-se retratos de celebridades segundo nichos específicos. Equivalentes aos retratos colecionáveis de astros e estrelas de Hollywood são as figurinhas de jogadores de futebol, por exemplo.

Do ponto de vista da materialidade, a técnica empregada indica a escala da produção. Para os retratos de astros e estrelas de Hollywood, adota-se a impressão fotográfica, mesmo existindo a possibilidade de impressão fotomecânica, o que pode ser indicativo da escala mais reduzida de produção deste produto. Outro dado que só a materialidade pode nos fornecer diz respeito ao processo de miniaturização. $O$ formato $3 \times 4 \mathrm{~cm}$ se consagrou como aquele ideal para os registros identitários. Qual a razão para a opção por este formato para retratos de celebridades? A portabilidade? Tudo leva a crer que esses retratos eram produzidos para serem arranjados em álbuns. Sua reduzida dimensão torna pouco prático o armazenamento 
senão acoplado a outro suporte. Mas até o momento não encontramos referências sobre álbuns para essas dimensões de retratos.

De todo modo, a miniaturização do retrato está relacionada a suportes que permitem a portabilidade junto ao corpo e antecede a fotografia. Os retratos na forma de silhuetas ou pintados à mão por miniaturistas para serem introduzidos em berloques, medalhões e camafeus era prática em voga na primeira metade do século XIX e se mantém para os retratos fotográficos. A moldura oval era recorrente, com o enquadramento de rosto ou busto. Uma versão moderna dessa prática pode ser encontrada nos chaveiros com retratos $3 \times 4 \mathrm{~cm}$ emoldurados por vidro ou plástico transparente, comuns nos anos 1950, 1960 e 1970, em diversos formatos.

O formato oval adotado como moldura gráfica para delimitar os retratos dos astros e estrelas de Hollywood de nossa coleção, assim como a ornamentação floral colorizada que a completa, podem ser vistos como parte dessa longa tradição de produtos destinados a serem carregados junto ao corpo, ainda que não fosse esse o destino final dos retratos em questão.

Importa atentar aqui que a prática de carregar junto ao corpo a imagem de alguém é um ato motivado pelo afeto, uma manifestação pública de afeição ao retratado, e também uma forma de resolver a ausência por meio de seu substituto, o retrato ${ }^{11}$. Ao adotar recursos visuais para os retratos de celebridades que se assemelham, nas dimensões e no formato de moldura, àqueles produzidos desde o século XIX e adotados no agenciamento de práticas afetivas, é possível pensar não só que os produtores idealizaram o produto tendo como referência essa tradição, mas que que esta tradição expressa materialmente também induz o estabelecimento de uma ilusória relação de intimidade e permeada pelo afeto, prerrogativa da condição de fãs.

O formato carte de visite introduzido por Disderi em 1854, embora apresentasse dimensões maiores do que as miniaturas $(10 \times 6 \mathrm{~cm})$, também respondia às demandas de portabilidade motivadas por práticas afetivas ${ }^{12}$.

11 A produção literária é pródiga em nos fornecer contextos de usos de objetos e, no caso, especialmente dos objetos visuais, como segue: "Qual é a mãe, qual é a avozinha, que não guarda, embrulhados em papel de seda, os brincos com que casou ou a medalha em que guardava o retrato do marido ou do filho?" (AZEVEDO, Aluísio de. Girândola de amores, p. 50) ou "Fidélia não deixou inteiramente o luto, trazia às orelhas dois corais, e o medalhão com o retrato do marido, ao peito, era de ouro" (ASSIS, Machado de. Memorial de Aires, p. 75).

12 Ver, a respeito, pesquisa recente sobre a dinâmica familiar envolvendo retratos em MUAZE, Mariana de Aguiar Ferreira. Os guardados da viscondessa: fotografia e memória na coleção Ribeiro de Avellar. Anais do Museu Paulista, v. 14, n. 2, p. 73-110, dez. 2006. 
E sua permanência e difusão parecem ter logrado amplitude para além da retratística fotográfica. A popularidade dos retratos neste formato gerou demandas para a produção de álbuns com "janelas" apropriadas. Um exemplo da permanência deste formato em outro circuito é também possível de ser identificado no conjunto do A41.

Os cerca de 160 impressos religiosos adquiridos em feiras de antiguidade ou integrantes de coleção familiar demonstram materialmente a permanência deste formato (Figura 3). Os impressos religiosos no formato

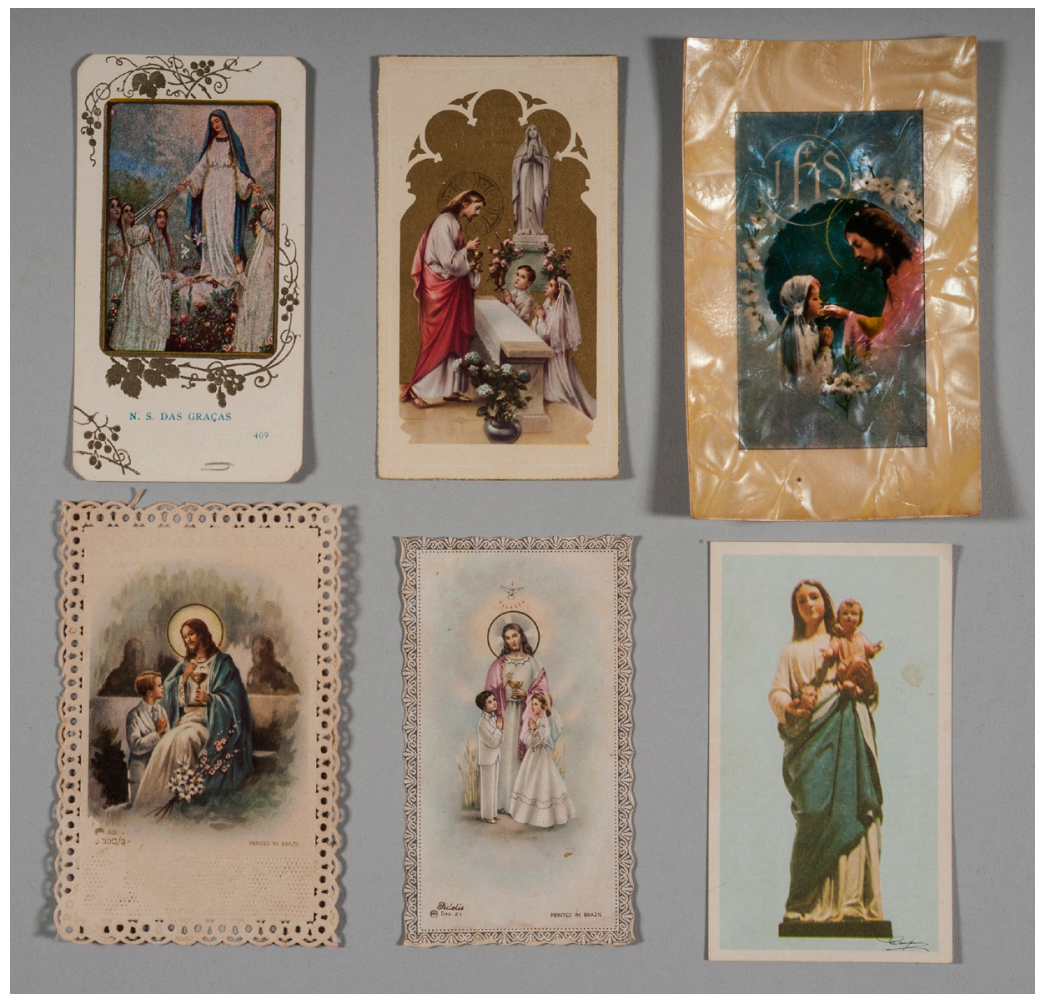

FIGURA 3 - IMPRESSOS RELIGIOSOS DIVERSOS REFERENTES AO RITUAL CATÓLICO DE PRIMEIRA COMUNHÃO. IMPRESSO FOTOMECÂNICO, 1959, 1984, SEM DATA, SEM DATA. DOCUMENTO AVULSO. ACERVO MUSEU PAULISTA DA USP. REPRODUÇÃO JOSÉ ROSAEL. 
$10 \times 6 \mathrm{~cm}$ ou ligeiramente maior $(11 \times 7 \mathrm{~cm})$ podem ser divididos em algumas categorias: imagens de santos, produzidas sob encomenda muitas vezes de um devoto como pagamento de graça alcançada; lembrança vinculada aos ritos em torno do falecimento, notadamente a missa de sétimo dia; lembrança de ritos de passagens na formação religiosa, como batizado, primeira comunhão, crisma. O formato portátil é desejável nesse caso, sobretudo porque, ao contrário dos retratos, os impressos religiosos não são acumulados em álbuns, mas circulam avulsos muitas vezes acondicionados em carteiras, bolsas.

Sua permanência como produto visual integrado ao cotidiano deve-se não só à prática católica, mas também, e novamente, à dimensão afetiva que envolvem. No caso, é digno de nota perceber a gama variada de tipos de impressão e recursos gráficos. Na categoria de materiais visuais sem classificação no mundo das artes, por sua total falta de autoria, originalidade de conteúdo visual e precariedade dos materiais e técnicas de impressão empregadas, são ignorados pelos museus de arte. Tampouco se tem notícias de sua presença em museus de antropologia. No entanto, para historiadores interessados nos problemas da visualidade, são essas mesmas características que podem ser tomadas como indicativas da abrangência e tentacular presença do visual em nosso cotidiano. Os impressos religiosos são produzidos em gráficas pequenas, encomendados por indivíduos, ou seja, passam ao largo de uma produção agenciada por grandes editoras ou empresas gráficas. Nesta produção, valem as investidas criativas de gráficos para particularizar o produto final para o cliente, que, via de regra, participa do processo com ajuda de repertórios de amostras. Os impressos aqui reproduzidos revelam essa variedade em um arco cronológico que vai da década de 1950 a 1970. A delicada ornamentação rendilhada no papel tem seu correspondente mais simplificado (e econômico) na impressão que a imita, por exemplo.

Outro conjunto que compartilha de características materiais semelhantes são os materiais visuais circulados na rede escolar. Adesivos para ilustrar trabalhos escolares (Figura 4), especialmente os trabalhos de História ou Organização Social e Política, matéria obrigatória no período da ditadura militar. A produção de retratos impressos a partir de fotografias respeita os enquadramentos típicos dispensados tradicionalmente a personalidades 


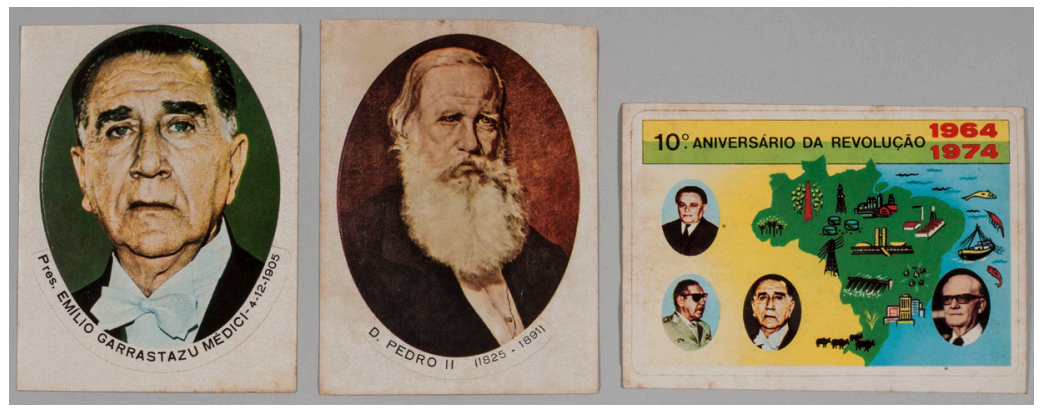

FIGURA 4 - MATERIAL DIDÁTICO. ADESIVOS PAPI, TIPO-LITO ATENA LTDA. SEM DATA. DOCUMENTO AVULSO. ACERVO MUSEU PAULISTA DA USP. REPRODUÇÃO JOSÉ ROSAEL.

políticas - a valorização do rosto em tomada frontal ${ }^{13}$. As dimensões dos adesivos são uma variação do formato vertical do carte de visite e estendem as funções de portabilidade para o circuito escolar, sem deixar de remeter à tradição do retrato de celebridade, neste caso, política.

As tipologias aqui tratadas de modo exploratório já permitem perceber como a materialidade atua na dinâmica da cultura visual contemporânea. A diversidade de origens, circuitos e cronologias dos suportes visuais recolhidos, por sua vez, nos remete para o papel dos museus nesse contexto.

\section{Usos, descartes, reciclagens e o museu}

A opção curatorial que orientou a alimentação do A41 considera esses objetos visuais também como objetos de afeto, vetores de performances individuais ou de grupo, que não esgotam seu potencial nas mensagens

13 Encontramos o uso da moldura oval na representação de personalidades políticas ou detentoras de cargos políticos em publicações do início do século XX, reforçando a tradição pictórica presente na própria ornamentação arquitetônica e pintura mural do Museu Paulista (cf. LIMA, Solange Ferraz de; CARVALHO, Vânia Carneiro de. Vistas urbanas, doces lembranças, o "antigo" e o "moderno" nos álbuns fotográficos comparativos. In: MURARI, Francisco (Org.). Antigos e modernos, diálogos sobre a (escrita da) história. São Paulo: Alameda, 2009. p. 405. 
do conteúdo iconográfico. As imagens são tratadas como artefatos, com vida social ativa e geradora de efeitos de toda sorte no cotidiano de seus primeiros detentores. A maioria dos suportes é, como Meneses qualifica, programaticamente destinada a terceirizar memórias - dos cartões postais como suvenires aos álbuns ou conjuntos de fotografias de família ${ }^{14}$.

Se o foco são também as performances, e o entendimento do lugar desses álbuns e coleções na vida dos indivíduos e na reprodução de suas relações sociais, torna-se imperioso o conhecimento de suas vidas pregressas. O curso de integração de objetos ao acervo do museu é o momento mais propício para recuperar essa vida pregressa. Momento para procurar entender, entre outras, as motivações dos indivíduos ao buscar o museu como destino final de seus objetos ${ }^{15}$ ou levantar hipóteses sobre as razões para $\mathrm{o}$ abandono de mais de 700 fotografias, como é o caso da coleção Família M., trazida ao museu pelo vizinho dos moradores que, ao mudarem, deixaram para trás o acervo fotográfico familiar. Esquecimento? Talvez.

Algumas situações reportadas pelos doadores no curso dessa integração merecem ser descritas para pensarmos como o museu ativamente desencadeia uma série de ações nessa rede social e como e por que esses suportes visuais entram e saem da vida das pessoas.

\section{Usos}

Os álbuns montados são particularmente de interesse como evidências materiais de práticas corporais e gestuais que envolvem dedicação do tempo vivido. São performances mobilizadas em torno da imagem-artefato que, por sua vez, agenciam outras práticas. A cola no papel, as inscrições, o arranjo, são todos indicativos de que ali há um tempo cooptado do cotidiano para a fatura de uma encadernação, desenvolvimento de habilidades para

14 MENESES, Ulpiano Toledo Bezerra de. História e imagem: iconografia/iconologia e além. In: CARDOSO, Ciro Flamarion. Domínios da História. Rio de Janeiro: Elsevier, 2012. p. 258.

15 Sobre o tema, cf. LIMA, Solange Ferraz de; CARVALHO, Vânia Carneiro de. Cultura material e coleção em um museu de história: as formas espontâneas de transcendência do privado. In: FIGUEIREDO, Betânia Gonçalves; VIDAL, Diana Gonçalves (Org.). Museus: dos gabinetes de curiosidades à museologia moderna. 1. ed. Belo Horizonte: Argumentum/CNPq, 2005. p. 85-110. 
os recortes de imagens; e as marcas do manuseio registram a fruição rotineira. As referências que encontramos aos álbuns em outras fontes escritas e orais permitem qualificar tais momentos no tempo como performances de caráter afetivo e emocional a serviço da rememoração. Em Arquivar a própria vida, Artiéres, a partir da pesquisa de Anne-Marie Garat, bem descreve esse processo:

Em toda família existe com efeito o hábito de dedicar regularmente longas tardes a reunir e a organizar as fotos relacionadas com a vida de cada um dos seus membros. Um casamento, um nascimento, uma viagem são objeto de uma ou de várias páginas. Não colamos qualquer foto nos nossos álbuns. Escolhemos as mais bonitas ou aquelas que julgamos mais significativas; jogamos fora aquelas em que alguém está fazendo careta, ou em que aparece uma figura anônima. E depois as ordenamos esforçando-nos para reconstituir uma narrativa. Quando a foto é muito enigmática, acrescentamos um comentário. Quando uma visita chega, começa a cerimônia das fotos, fazem-se as observações, viram-se algumas páginas rapidamente. Acontece, também, com o tempo, de algumas fotos serem retiradas, porque são comprometedoras, porque não são condizentes com a imagem que queremos dar de nós mesmos e da nossa família. Pois o álbum de retratos constitui a memória oficial da família; só raramente os amigos têm um lugar nele. $\mathrm{O}$ essencial é que em alguns minutos, uma hora no máximo, possamos justificar o tempo passado e a sua coerência. Sob esse ponto de vista, as páginas dedicadas às viagens são muito significativas. Exibimos provas mostrando, por exemplo, a família au grand complet diante de um monumento. No álbum, fazemos figurarem também os nossos antepassados; aí também trata-se de comprovar que pertencemos a uma linhagem, que temos raízes. Quando um antepassado é embaraçoso, ou porque ficou louco, ou porque teve uma atitude pouco apropriada, suprimimos sua presença: pintamos sua cara de preto ou retiramos sua foto. Se as audiências nos álbuns são toleradas, não manter arquivos fotográficos da família, em compensação, constitui uma falta. É um dever produzir lembranças; não fazê-lo é reconhecer um fracasso, um passaporte de sinceridade e uma prova de ajustamento. ${ }^{16}$

Por essas ações fica claro que a existência material das fotografias desempenha papel de igual importância aos seus significados imagéticos.

16 ARTIÉRES, Philippe. Arquivar a própria vida. Revista Estudos Históricos, CPDOC/FGV, v. 11, n. 21 , p. 9-34, 1998. p. 14. 
Elizabeth Edwards problematiza o lugar das fotografias nos museus quando estas são pensadas para além do visual. Esta perspectiva exige atenção para o que considera uma fusão e uma interação performática da imagem e de sua materialidade ${ }^{17}$, como podemos supor acontecer na montagem de um álbum familiar. Essa perspectiva implica considerar aspectos concernentes às subjetividades - sentimentos e emoções - às quais a fotografia encontra-se irremediavelmente conectada, atuando como gatilho.

No caso presente, alguns relatos coletados, somados aos indícios materiais de usos desses objetos, nos colocam nessa direção. A doação de S.G.C. é um caso. A senhora Silvia (nome fictício) nos procurou de modo espontâneo, motivada pelas matérias sobre retratos que haviam sido divulgadas após a inauguração da exposição Olho cíclico (2003). Trazia consigo 66 retratos de família soltos, acondicionados em envelopes. Não havia no verso nenhum tipo de identificação (nomes, datas).

No momento da entrevista para elaboração do laudo de interesse histórico, apontamos as dificuldades com fotografias sem identificação e a Sra. Silvia se dispôs a essa tarefa. Retornou alguns dias depois, nós a acomodamos no segundo andar do Serviço de Documentação Textual e Iconográfico. No final da tarde ela havia terminado seu trabalho. A Sra. Silvia encontrava-se visivelmente emocionada quando nos entregou o conjunto identificado. E seu relato neste momento reportou a emoção que sentiu ao longo daquelas horas de fruição da coleção de retratos de sua família. A necessidade de nomear e datar cada uma das fotografias foi acompanhada de um momento de rememoração, permeado por sentimentos de nostalgia. Pudemos assistir, assim, naquele momento, as fotografias em ação, provocando efeitos.

Este exemplo é único neste aspecto. Mas outros relatos manifestos por doadores no ato da doação, ainda que menos emocionados, sempre trazem na voz, no gesto de exposição do conjunto selecionado para a doação, notas da expectativa quanto ao novo destino, quanto ao valor que iremos atribuir ao seu legado. Trata-se de uma prática contemporânea, cujas motivações estão ainda por ser melhor estudadas e não é pretensão deste artigo aprofundar tais questões, que requerem percorrer caminhos metodológicos da Psicologia Social, da Antropologia dos Sentidos ou de uma Sociologia

17 EDWARDS, Elizabeth. Photographs and History. Emotion and materiality. In: DUNDLEY, Sandra H. (Ed.). Museum Materialities. Objects, engagements, Interpretations. London/New York: Routledge, 2010. p. 23. 
das Emoções. Importa frisar, no entanto, que essas perspectivas não podem ser ignoradas por uma prática curatorial comprometida com problemáticas históricas. Trata-se de reconhecer a cultura visual como muito mais ampla e complexa do que um conjunto de produtos valorizados exclusivamente pelos significados de seus conteúdos visuais. Um desafio para curadores, portanto, que precisarão lidar com conteúdos, as evidências materiais, mas também com as trajetórias e performances desses objetos.

Ainda nesse sentido, devemos ressaltar a recorrência de doações de colecionadores. As reflexões acerca do colecionismo privado e o papel do museu também como colecionador mobilizam muitos pesquisadores. A museóloga Susan Pearce, por exemplo, tem desenvolvido pesquisas com o intuito de definir o perfil de colecionadores $(1992,1996)$ e das coleções e a prática colecionista é também tratada no campo da psicologia social ${ }^{18}$.

Os muitos pesquisadores que se dedicam ao tema concordam, em linhas gerais, com a definição apresentada por Belk: “[...] colecionar é o processo de, ativa, seletiva e passionalmente, adquirir e possuir coisas deslocadas do uso cotidiano e tomadas como parte de um conjunto de objetos não idênticos." $" 19$

Recorrentes nos processos de doações que recebemos são as coleções de cartões postais. No A41 figuram duas coleções com este perfil. Uma delas, de um conhecido colecionador paulistano, é bem típica - com um recorte claro, composta por exemplares adquiridos em feiras. A outra coleção foi trazida pessoalmente pela colecionadora e reúne 559 cartões postais de cidades da Europa (décadas de 1970 e 1980). Além do recorte temático, a coleção M.B. tem a característica de reunir, na sua grande maioria, postais recebidos de amigos quando em viagens. Nesse caso, a coleção era alimentada por uma rede de pessoas conhecidas, familiares, amigos distantes ou íntimos. Diante do relato de como a coleção se formara, a pergunta evidente era por que se desfazer de algo que ia além de uma prática focada

18 PEARCE, Susan M. Museum Objects. In: (Ed.). Interpreting Objects and Collections. London: New York: Routledge, 1996. p.9-11. PEARCE, Susan M. Museums Objects and Collection. A Cultural Study. London: Leicester University Press, 1992. DANET, Brenda; KATRIEL, Tamar. No Two Alike: Play and Aesthetics in Collecting. In: PEARCE, Susan (Ed.). Interpreting Objects and Collections. London: New York: Routledge, 1996. p. 220-239.

19 Tradução livre da autora de: “...collecting is the process of actively, selectively, and passionately acquiring and possessing things removed from ordinary use and perceived as part of a set of non-identical objects or experiencies. In: BELK, Russell W. Collecting in a Consumer Society. London/ New York, 2001 (1. ed. 1995). p. 67. 
nas particularidades da tipologia do postal e que deveria ter, certamente, um valor afetivo em virtude das inscrições no verso, todas dirigidas a ela e sua família. A resposta foi até certo ponto desconcertante. "Não cabe mais. Não sei o que fazer com tantos postais, eu vi que vocês investem em adquirir cartões postais, pensei que os meus poderiam interessar, e não ia me sentir bem jogando-os fora."

O que nos faz pensar sobre a prática colecionista e suas relações com o acúmulo, o excesso de bens, que acabam por provocar o desejo de descarte. E é aí que o museu surge como lugar de destino.

\section{Descartes e os museus}

Ao longo dos anos de curadoria e recepção de conjuntos documentais foi possível identificar, claramente, quais as ações do Museu e especialmente das curadorias de acervos visuais que provocaram movimentos de doações. A difusão nas mídias impressa e televisiva de projetos de curadoria e exposições serviu como gatilho para as doações espontâneas, como acima referido.

As afirmações de curadores sobre a necessidade de o Museu Paulista ampliar e diversificar o perfil das doações apoiadas no pressuposto de que um museu de história não deve ser o lugar para o objeto de exceção, da personalidade de exceção (política, por exemplo), mas que a história da cultura material precisa, necessariamente, ser representativa da sociedade em seus vários estratos, repercutiu de modo positivo, haja vista o aumento de doações advindas de distintas camadas da sociedade nos últimos 15 anos.

O A41 é exemplar neste sentido e por isso nos serviu aqui para este exercício de entendimento de alguns aspectos da cultura visual na sociedade atual, entre eles, o movimento de descarte. Mesmo considerando que as motivações que levam os indivíduos a doar objetos de sua esfera privada para um museu sejam os mais nobres e altruístas - desejo de homenagem a familiares, desejo de contribuir com o estudo de determinado segmento da cultura material -, trata-se de um ato de descarte de algo que integrava a vida pessoal. Ou seja, objetos doados são, por excelência, objetos que cessaram de desempenhar funções no contexto de vida desses indivíduos, 
ainda que essas funções estivessem relacionadas à manutenção de memórias afetivas e processos de construção de identidades.

Assim, como podemos interpretar a prática de destinar a uma instituição os suportes que, como denominou Meneses, foram feitos para programaticamente suportar memórias familiares ou proporcionar meios para práticas colecionistas vinculadas à construção da identidade social do indivíduo?

Podemos pensar que, como ato pessoal, o descarte pode ser lido como uma das maneiras de os indivíduos se redesenharem, mudarem suas dinâmicas de vida, se reinventarem. E os objetos podem ser os meios para efetivar essas ações ${ }^{20}$ e simbólica e materialmente representar essas mudanças. E é nesse contexto que podemos considerar os museus como copartícipes ativos neste processo, garantindo um lugar apropriado para o destino daquilo que não cabe mais na nova vida.

São dessa ordem as questões que podem ser encaminhadas a partir da reflexão do tempo das imagens na vida cotidiana e como parte de acervos museológicos.

Recebido em: 13/ 05/ 2014

Aprovado em: 27/ 06/ 2014

20 Para se evitar a naturalização deste processo, vale a pena refletir sobre como distintas culturas lidam de modo distinto com a cultura material acumulada privadamente ao longo da vida, não sendo o descarte o destino óbvio. Vejamos. O Axexê é um ritual fúnebre do candomblé, religião que condensa elementos e práticas da cultura Nagô, aqui conhecida graças à presença africana desde o século XVIII. Nele estão prescritas as etapas do ritual, entre as quais a atitude diante dos pertences materiais do iniciado falecido. A consulta ao oráculo (Búzios) é determinante para a distribuição dos pertences pessoais entre familiares e membros da comunidade religiosa à qual o falecido fazia parte. Após essa etapa de distribuição, os pertences remanescentes devem ser triturados com marretas e "devolvidos para a natureza" (é também o oráculo que define a forma de devolução, se enterrado, jogado ao mar, rio). O ritual remonta a uma cultura de pouca, mas preciosa acumulação material na qual os bens são destinados aos pares ou "morrem" com seu dono, os restos materiais são devolvidos para a terra, de onde tudo vem e, assim, integram a engrenagem do eterno renascimento. Cf. SANTOS, Juliana Elbein dos. Os Nagô e a morte. Petrópolis: Vozes, 1986. p. 234. Na prática budista moderna entre os tibetanos, as fotografias gozam de um lado de sua prerrogativa de verossimilhança, como na cultura ocidental, mas elas também foram integradas a rituais diversos e tradicionais, nos quais atuam como encarnações de suas representações icônicas, como relatado por Clare Harris. Em sua pesquisa sobre como as fotografias são entendidas neste contexto religioso e cultural, a autora procura demonstrar "... that photographs are often not just of bodies (having lives) but treated had been as bodies that can be born, become ill and die" (p. 139). Retratos que "morrem" devem ser incinerados e suas cinzas podem ser misturadas com argila, à semelhança da prática do $t s a$ tsa, que consiste em misturar as cinzas do corpo cremado de monges com argila para criar tabletes votivos. Acredita-se que as partículas da pessoalidade (personhood) do figurado na fotografia possam ser reinseridas, assim, à dinâmica da vida cotidiana e voltar a circular de maneira apropriada. HARRIS, Clare. The Photograph Reincarnate. The dynamics of Tibetan relationships with photography. In: EDWARDS, Elizabeth; HART, Janice. Photographs objects histories. On the materiality of images. London \& New York: Routledge, 2003. p. 132-147. 